\title{
A DIVISÃO LICENCIATURA/BACHARELADO NO CURSO DE EDUCAÇÃO FÍSICA: O OLHAR DOS EGRESSOS
}

\author{
LA DIVISIÓN PROFESORADO/LICENCIATURA EN EL CURSO DE EDUCACIÓN \\ FÍSICA: LA MIRADA DE LOS EGRESADOS
}

\author{
THE DIVISION BETWEEN TEACHER TRAINING AND BACHELOR'S DEGREES \\ IN PHYSICAL EDUCATION: THE GRADUATES' VIEW
}

Jacob Alfredo lora*, Maristela da Silva Souza*, Adelina Lorensi Prietto*
Palavras chave:

Educação Física.

Prática profissional.

Currículo.

Emprego.
Resumo: Este estudo investigou as demandas relativas à formação encontradas pelos egressos dos Cursos de Educação Física Bacharelado e Licenciatura ao se defrontarem com o mercado de trabalho. Para realizar esta pesquisa, utilizou-se o levantamento de dados nos cursos ofertados por uma instituição de ensino superior. A análise e a interpretação dos dados foram realizadas por meio da triangulação de dados considerando as categorias metodológicas da dialética materialista. As respostas expressaram que a divisão da Educação Física tem gerado inúmeros problemas para os profissionais no mercado de trabalho, ocasionados pela fragmentação de conhecimentos, pela falta de articulação entre teoria e prática e pela gerência do Conselho Regional de Educação Física e do Conselho Nacional de Educação Física.
Keywords: Physical Education. Professional practice.

Curriculum.

Employment.
Abstract: This study looked into the training demands found by graduates in Physical Education Bachelor's and Teacher Training Degrees when they entered the job market. This study collected data in courses offered by a higher education institution. Data analysis and interpretation were carried out by triangulating those data under methodological categories from materialist dialectics. Answers expressed that aforementioned the division of Physical Education has created several problems for professionals in the job market, caused by knowledge fragmentation, lack of connection between theory and practice, as well as by the management of the Physical Education Regional Council and the Physical Education National Council.

Palabras clave: Educación Física. Práctica profesional. Currículum. Empleo.
Resumen: Este estudio investigó las necesidades relativas a la formación que los egresados del curso de Educación Física Licenciatura y Profesorado encontraron cuando ingresaron en el mercado de trabajo. Para realizar esta investigación se utilizó la recogida de datos en los cursos ofrecidos por una institución de enseñanza superior. El análisis y la interpretación de los datos se realizaron a través de su triangulación, considerando las categorías metodológicas de la dialéctica materialista. Las respuestas expresaron que la división de la Educación Física ha generado varios problemas para los profesionales en el mercado laboral, debido a la fragmentación de los conocimientos, a la falta de articulación entre teoría y práctica y por la administración del Consejo Regional de Educación Física y del Consejo Nacional de Educación Física.
*Universidade Federal de Santa Maria. Santa Maria, RS, Brasil. E-mail: jacobiora07@gmail.com

Recebido em: 13-04-2016 Aprovado em: 15-03-2017 


\section{INTRODUÇÃO}

O processo de transformação na formação inicial se inicia com as Diretrizes Nacionais para a Formação das Licenciaturas, instituídas pelo Conselho Nacional de Educação (CNE) no ano de 2002. O discurso circunscrito ao entorno da comunidade acadêmica do Centro de Educação Física e Desportos (CEFD) era o de que tais mudanças fortalecem os conhecimentos da área da Licenciatura, pois os professores formados nos cursos unificados, durante a formação inicial, pouco adquiriam experiência na área da Educação Básica.

Em relação ao Curso de Bacharelado em EF do CEFD, as justificativas apresentadas para a sua criação estão amparadas legalmente na Resolução CNE/CES 07/2004 e no Parecer CNE/CES 058/2004. Nesse sentido, Morschbacher (2012) expõe que, naquele momento histórico, a divisão do Curso se justificou pela crescente expansão do mercado de trabalho e pelas mudanças na legislação referente à formação de professores para a atuação na Educação Básica, em sintonia com o sistema Conselho Federal de Educação Física e Conselho Regional de Educação Física. (CONFEF/CREF).

Nesse mesmo período, Nozaki (2004) já realizava uma análise crítica da regulamentação da profissão relacionada às questões do mundo do trabalho e formação profissional, apontando o reordenamento no campo educacional e da Educação Física brasileira. Pelo agravamento da crise do capital, são retomados projetos neoconservadores, por meio de políticas neoliberais, que atingiram também o campo educacional.

Segundo Taffarel (2012), ao elaborar a crítica sobre a divisão na formação inicial, o principal objetivo que está inserido nessa tendência é desregulamentar o trabalho por meio do ajuste especializado da formação inicial. Esses mecanismos fragilizam o trabalhador pelas vias do esvaziamento teórico e pela delimitação nos campos de trabalho.

Um estudo que demonstra claramente isso é o de Both (2011, p. 60), que, de maneira sintética, analisou as mediações das mudanças no mundo do trabalho, no marco da luta de classes e na EF. $\mathrm{O}$ autor, em seus estudos, aponta a perda da centralidade do componente curricular da EF no âmbito educacional e alerta para a realidade da EF como parte de um mercado de "[...] prestação de serviços, terceirizado e precário, com poucos direitos trabalhistas que se concentra na lógica da privatização e da mercadorização dos conteúdos da Cultura Corporal".

Atualmente, a EF está dividida em dois campos: o campo escolar e o não escolar, e essa divisão se constitui numa importante mediação entre a EF e as novas necessidades do trabalho. Os trabalhadores estão tendo de se adaptar às necessidades que o mercado de trabalho exige, o que os leva ao trabalho informal, precário e com poucos direitos.

A justificativa desse processo dual de formação é que o profissional formado a partir do novo currículo se sentiria seguro e competente para atuar no campo específico ao qual é direcionado. A consequência das reformas curriculares apontadas por Morschbacher (2012) é a fragmentação da formação do trabalhador em EF, tendo como parâmetro fundamental a divisão dos espaços de trabalho: escolares e não escolares.

Esse argumento é questionado por autores como Taffarel e Santos Júnior (2010, p. 35), que afirmam que a pretendida distinção entre licenciados e bacharéis em EF, tendo como referência esse aspecto, desconsidera o elemento unificador desses trabalhadores, que é 0 trabalho pedagógico e/ou docente: "No caso da Educação Física significa, em última análise, 
o reconhecimento de que onde quer que atuemos (escola, academias, clubes, praças, etc.), o que nos unifica e nos dá identidade é o trabalho docente."

Apresentamos como objetivo geral deste estudo investigar as demandas relativas à formação, encontradas pelos egressos dos cursos de EF Licenciatura e Bacharelado ao se defrontarem com o mundo do trabalho, bem como, de forma específica, entender o motivo pelo qual os estudantes egressos retornam para complementar sua formação no outro curso de graduação em EF, verificar se os currículos dos cursos do CEFD estão correspondendo às necessidades dos futuros professores em relação às suas atuações no campo de trabalho e compreender, no sentido subjetivo ${ }^{1}$, qual o sentimento do acadêmico ao prolongar por até oito anos a formação em EF.

Sendo assim, a partir do grande número de egressos que retornam para complementar a sua formação inicial, consideramos importante analisar essas questões com 0 intuito de avaliar e relacionar a formação oferecida pelo Centro de Ensino que contempla os cursos de bacharelado e licenciatura em EF, com as demandas e necessidades encontradas pelos professores no mercado de trabalho. Diante disso, este estudo se justifica por buscar entender como está sendo esse retorno à formação acadêmica.

\section{METODOLOGIA}

Nesta etapa, pretendemos apresentar os passos que foram construídos durante 0 desenvolvimento deste estudo. Entendemos que a realidade educacional deve ser estudada como parte das Ciências Sociais, em que o fenômeno passa a ser analisado na sua totalidade e compreendido como parte desta, possibilitando, assim, uma maior compreensão da realidade.

Poderíamos compreender a realidade dos cursos de graduação do CEFD a partir do modelo "[...] científico natural, regido por processos baseados em cálculos e probabilidades, livres da explicação causal dos fenômenos e de construções e explicações ideológicas ou utópicas" (LOWY, 1998, p 11). Esse método de explicação apenas nos apresenta a análise singular do fenômeno que se situa em analisar quantitativamente a relação de alunos egressos que retornam ao CEFD para realizar o curso de graduação na outra área de conhecimento da Educação Física. Essa análise não abrangeria o trabalho que reflete a causa do retorno na formação (geral), tampouco as relações de mercado de trabalho (particular) apresentadas para da divisão Educação Física Licenciatura/Bacharelado.

A lógica dialética toma por base o princípio da unidade entre 0 abstrato (reflexo no pensamento) e o concreto (real materializado) no pensamento teórico-científico, diferenciandose de Hegel, que entendia o movimento abstrato - concreto - abstrato. Para Kopnin:

[...] 0 movimento do pensamento do abstrato para o concreto é um meio para obtenção da autêntica objetividade do conhecimento [...] o método de ascensão do abstrato ao concreto é apenas um meio pelo qual o pensamento aprende 0 concreto e o reproduz como espiritualmente concreto (KOPNIN, 1978, p. 66).

\footnotetext{
1 Compreender o conhecimento subjetivo significa, neste trabalho, compreender o ponto de vista pessoal e individual, o sentimento e as sensações dos egressos do curso de EF que retornam à formação inicial. Porém, nossas análises estão fundadas nas análises objetivas e concretas deste trabalho.

2 A definição de ideologia e utopia está situada neste trabalho de acordo com Lowy (1998). Tanto as ideologias quanto as utopias podem ser chamadas de visões sociais de mundo, havendo visões sociais de mundo utópicas e visões sociais de mundo ideológicas. As visões ideológicas seriam denominadas dessa forma quando visassem à manutenção da ordem estabelecida e as visões utópicas, quando visassem uma ruptura com essa ordem.
} 
Marx (2011), ao estabelecer as relações de troca de mercadorias na sociedade capitalista, afirma que cada produto é considerado sob duplo aspecto. No primeiro deles, a quantidade expressa a proporção de trabalho empregado em cada produto, para que este possa ser trocado por outro, expressando relação de igualdade. A diferença quantitativa em que um produto expressa valor no outro é definida também pelas propriedades qualitativas, como, por exemplo: "[...] dada quantidade de trigo se iguala a alguma quantidade de ferro" (MARX, 2011, p. 59).

Outra categoria a ser considerada é a luta de classes (luta dos contrários), que determina o processo de produção contraditório, de um lado capitalista, com o objetivo da maior expansão possível do próprio capital, por meio da exploração possível da força de trabalho. Do outro lado, o trabalhador como proprietário somente da sua força de trabalho a emprega e exerce a resistência na medida em que cresce o número de trabalhadores empregados.

$\mathrm{Na}$ análise e intepretação, foi utilizado o procedimento de triangulação de dados, que, segundo Triviños:

[...] tem por objetivo básico abranger a máxima amplitude na descrição, explicação e compreensão do foco em estudo. Parte de princípios que sustentam que é impossível conceber a existência isolada de um fenômeno social, sem raízes históricas, sem significados culturais e sem vinculações estreitas e essenciais com uma macrorrealidade social (TRIVIÑOS, 1987, p. 138).

Partindo desse procedimento, realizamos a análise dos Projetos Pedagógicos dos Cursos de Graduação em Educação Física Licenciatura e Educação Física Bacharelado na instituição investigada e das Resoluções CNE/CP 01/2002 e CNE/CES 07/2004, que instituem as Diretrizes Curriculares Nacionais para os respectivos cursos. Combinamos 0 levantamento bibliográfico com a pesquisa de campo, em que através do número de alunos que retornaram para complementar sua formação de maneira abrangente, compreendemos, por meio de entrevistas com nove egressos de Cursos de Educação Física, os motivos que os levaram a retornar para a formação inicial. Na sequência, contrastamos as análises das entrevistas realizadas com os egressos com as análises dos documentos sobre o Curso de Educação Física. No primeiro momento, foram realizados estudos relativos ao referencial teórico, utilizando-se de uma literatura que abordou os seguintes temas: o processo histórico da formação de professores do Centro em questão e as transformações no mundo do trabalho.

As categorias de conteúdo - o objetivo do retorno dos estudantes, a formação e 0 mundo do trabalho e a ampliação no tempo de permanência (subjetivo) - foram construídas levando em conta o que propõe Minayo (1993, p. 70), para quem essa técnica de tratamento de dados pode ser entendida com o seguinte conceito: "[...] agrupar elementos, ideias ou expressões em torno de um conceito capaz de abranger tudo isso". Para a análise e discussão dos resultados, serviram de base as leis e categorias metodológicas da dialética materialista: quantidade e qualidade, luta de classes, abstrato e concreto, lógico e histórico.

\section{OS PROJETOS CURRICULARES DO CENTRO ESTUDADO}

O primeiro currículo do Curso de Graduação em Educação Física do CEFD da Universidade Federal de Santa Maria (UFSM) seguiu a orientação do Conselho Federal de Educação (CFE), tendo como referência a Resolução no 20.68/69. O segundo currículo do Curso de Educação Física Plena, de caráter unificado, foi implantado em 1990, baseado 
na Resolução CFE 03/87, de 16 de junho de 1987 (p. 2), tendo como objetivo formar "[...] profissionais capazes de contribuir para o desenvolvimento harmônico do indivíduo, com uma concepção transformadora-inovadora, fundamentados em áreas de conhecimento técnico, conhecimento do homem, conhecimento filosófico e conhecimento da sociedade". A definição da profissão se dá por meio da formação biopsicossocial e educação de crianças, adolescentes e adultos, fundamentando-se em áreas de conhecimento técnico e conhecimento do ser humano. Assim, a versão do currículo de 1990 habilitava o profissional do movimento humano com ênfase no esporte, ginástica, recreação e dança.

O currículo atual do Curso de Educação Física Licenciatura Plena foi criado em 2004, orientando-se na Lei de Diretrizes e Bases da Educação Nacional - LDB 9.394/96 - e fundamentando-se na Resolução CNE/CP 01/2002 e na Resolução CNE/CP 02/2002. Assim, inicialmente, a instituição apresentou, no ano de 2005, o Curso de Licenciatura Plena, com o foco na formação para atuação na Educação Básica no sentido de: desenvolver ações teórico-práticas em que os conhecimentos e saberes acadêmicos contribuam na formação do ser humano em sua totalidade e possibilitar uma formação político-social, dentro de uma abordagem histórico-crítica, em diferentes manifestações da cultura corporal, compromissada com a educação emancipatória.

O Curso de Bacharelado teve início no primeiro semestre de 2006 e foi instituído pela Resolução CNE/CES 07/2004 e pelo Parecer CNE/CES 058/2004. O Projeto Políticopedagógico (PPP) do Curso tem como objetivo:

\begin{abstract}
A formação de profissionais habilitados para atuarem no ensino formal e não formal nos institutos e órgãos de pesquisa, nas instituições de promoção da saúde e de tratamento de doenças, como também possibilitar uma formação técnico-profissional visando o aperfeiçoamento de habilidades, capacidades e competências necessárias ao exercício profissional/docente. (Projeto político pedagógico do Curso de Educação Física Bacharelado ${ }^{3}, 2006$, p. 6). ${ }^{4}$
\end{abstract}

Taffarel (2012) é uma das autoras que criticam as atuais diretrizes curriculares e a divisão na formação dos professores de EF. Ela apresenta uma proposta de diretrizes curriculares para um curso de licenciatura plena, de caráter ampliado, instituído na Universidade Federal da Bahia (UFBA), em que o licenciado em EF "[...] terá como campo de ação: - o ensino em escolas de $1^{\circ}$ e $2^{\circ}$ graus e Universidades; - 0 ensino em Academias; - a orientação de atividades desportivas" em ambos os espaços de atuação (FACED/UFBA, 2011, p. 1).

\title{
40 TRABALHO, SUAS TRANSFORMAÇÕES E A RELAÇÃO COM A EDUCAÇÃO FÍSICA
}

Para Marx (2011), o trabalho ${ }^{6}$, antes de qualquer coisa e independente da formação social a que está submetido, é indispensável e essencial para a existência humana. Ao mesmo tempo em que o ser humano transforma a natureza, ele se apropria do conhecimento construído transformando a si mesmo. Para Antunes (2005, p. 68), "[...] esse processo de transformação recíproco faz com que o trabalho social se converta em elemento central do desenvolvimento da sociabilidade humana".

\footnotetext{
3 Documento interno do curso de Educação Física Bacharelado do Centro de Educação Física e Desportos, Universidade Federal de Santa Maria. 4 Projeto Político Pedagógico. Curso de Educação Física Bacharelado. Documento interno, impresso CEFD, 2006.

5 Faculdade de Educação da Universidade Federal da Bahia.

6 Não é intenção deste artigo aprofundar a categoria trabalho. Referendamos, para este fim, os estudos de Both (2015), Antunes (2002), Nozaki (2004), Marx (2011), Faria (2004).
} 
Para Antunes (2005), a partir da crise de 1980 surge um novo caráter multifacetado do trabalho. É uma noção contemporânea que se expressa na execução de trabalhos parciais, precarizados e no aumento do número de desempregos. Isso acontece porque o capital precisa cada vez menos do trabalho estável e cada vez mais de trabalho part-time, terceirizado, que cresce a cada dia no mundo produtivo industrial de serviços.

A partir da década de 1980, houve grandes transformações no mundo do trabalho7, novas experiências de trabalho começaram a se mesclar com outros processos produtivos existentes, dando origem ao modelo toyotista ${ }^{8}$. No Brasil, todas essas mudanças estruturais aconteceram em meados da década de 1990, com a implementação dos propósitos neoliberais pelo Governo Federal, em especial no mandato de Fernando Henrique Cardoso (FHC). Dentro desse processo, os desempregados, os mais necessitados do campo e das cidades e os assalariados precarizados começaram a buscar um lugar no novo mercado de trabalho.

Segundo Nozaki (2004), o mercado de trabalho diz respeito aos espaços onde é mais fácil aos trabalhadores vender a força de trabalho, provendo a sua subsistência. Porém, a forma alienada e precarizada com que a classe trabalhadora se submete aos ditames do mercado de trabalho faz com que ela continue reproduzindo e perpetuando a entrega da sua própria força de trabalho para o capital.

A educação nesse novo propósito, sob a ótica da formação profissional, busca adaptar o futuro trabalhador num mundo globalizado e competitivo. Segundo Gentili (1995), no campo educacional, a busca da qualidade assume grande parte dos conteúdos que esse debate possui no campo produtivo-empresarial. Essa lógica, que busca ajustar a educação ao mercado, pressupõe três premissas:

a. que educação (nas atuais condições) não respondeàs demandas eàs exigências do mercado; b. que a educação (em condições ideais de desenvolvimento) deve responder e ajustar-se a elas; c. que certos instrumentos (científicos) de mediação nos permitem indagar acerca do grau de ajuste educação-mercado e propor os mecanismos corretivos apropriados (GENTILI, 1995, p. 156).

Nesse sentido, seguindo as demandas do mercado de trabalho, "ajusta-se" a formação em Educação Física sob o viés da promoção da saúde e da melhoria da qualidade de vida, pois se multiplicam as atuações dos professores de EF em espaços como academias de ginástica, clubes e demais espaços de lazer. Nozaki (2004), contudo, alerta para a precarização do trabalho, que parte do trabalho assalariado (trabalho formal) nas escolas e chega ao setor de bens e serviços, que, muitas vezes, acontece na informalidade.

\section{QUE REVELAM OS EGRESSOS}

Buscando abranger o universo da totalidade, realizamos o levantamento de dados, contando com o auxílio do Departamento de Registro e Controle Acadêmico (Derca). Foi apurado o número total de 42 pessoas que, durante o período de 2008 a 2015, realizaram ou estão realizando a formação inicial em ambos os Cursos. O levantamento realizado pelo Derca

7 Para Nozaki (2004, p. 2), a noção de mundo de trabalho analisa os "[...] aspectos centrais e estruturais acerca das relações de confronto entre capital e trabalho que determinam justamente o campo e o mercado de trabalho".

80 modelo de trabalho toyotista é baseado em mecanismos flexíveis do trabalho atual. A partir de Faria (2004), trabalhar-se-á cooperação gerencial, os círculos de controle de qualidade (CCQ), os quais constroem grupos de trabalho responsáveis por corrigir ou tomar providências em relação à produtividade e reformulações desenvolvidas nas matrizes japonesas que atingiram os objetivos de aumentar a qualidade e a produtividade e baixar o custo da produção. 
remete a sujeitos somente do Centro, os quais possuem ou possuíram duplas matrículas, sendo 21 professores que retornaram ao Curso de Educação Física Bacharelado e 21 profissionais que retornaram ao Curso de Educação Física Licenciatura, com o objetivo de complementar a sua formação no sentido ampliado.

Objetivando demonstrar que essa divisão alcança o universo de formação inicial da EF para além da instituição estudada, realizamos o levantamento de dados quantitativos em relação a acadêmicos egressos de outras Instituições de Ensino Superior, que se encontram neste semestre realizando a sua segunda formação inicial. Esse levantamento remete ao acréscimo de nove estudantes, totalizando 51 egressos que retornam aos Cursos de Graduação em EF.

Podemos inferir inicialmente que a divisão do Curso de Licenciatura do CEFD/UFSM reduziu em $50 \%$ o número de formação de Licenciados pela divisão 60 vagas Licenciatura e 60 vagas Bacharelado, indo ao encontro do que relatam as DCNs (2015).

Além disso, estamos oportunizando a formação em Nível Superior para um menor número de trabalhadores, pois, considerando o recorte desta pesquisa, do total de 840 vagas ofertadas em sete anos de ingresso, 6\% (51 vagas) foram ocupadas pelos graduados. Isso significa que a divisão não traz prejuízo somente para os graduados que despendem mais tempo para a formação ampliada. A divisão do Curso retira oportunidades de pessoas ingressarem na formação em Nível Superior (6\% das vagas), pois não se conhece nenhum caso de realização de dupla graduação em Educação Física anterior à divisão do Curso.

Durante a investigação, realizada a partir de entrevista semiestruturada, os acadêmicos nos revelaram que os problemas do Curso vão além da divisão Bacharelado/Licenciatura. Para eles, algumas disciplinas contribuem pouco para a sua formação, e essa precariedade tornase mais aparente à medida que 0 acadêmico progride no Curso. Na opinião da Professora $F$, os docentes do Centro deveriam ter uma maior sensibilidade, já que "[...] eles estão formando futuros profissionais".

Dando continuidade ao processo de análise e interpretação dos dados, definimos as categorias de análise que melhor respondiam aos propósitos da investigação. Assim, foram definidas as seguintes categorias: o objetivo do retorno dos estudantes; a formação e o mundo do trabalho; e a ampliação no tempo de permanência (subjetivo). Dentre as informações levantadas, agrupamos as respostas mais incisivas e expressivas sobre cada categoria, embora todas tenham sido significativas para este trabalho.

Tendo em vista o processo de construção dos currículos dos Cursos de Educação Física Licenciatura e Bacharelado do CEFD, que denotou o direcionamento dos conhecimentos a serem adquiridos em cada área, o primeiro aspecto revelado pela análise foi a negação do conhecimento gerado pela divisão, expressada da seguinte forma pelos professores graduados nos Cursos de Licenciatura e Bacharelado:

Ah, formação inicial, hoje em dia, ela deixa muitas lacunas, assim, tipo Educação Física Licenciatura nega um pouquinho o conhecimento biológico. Tu vai ser professor, tu tens também que ter conhecimento quando tu fores trabalhar com 0 teu aluno na escola. (Professor E, Licenciatura).

Já na área do Bacharelado, a negação do conhecimento se refere ao trato pedagógico, expressado no relato: 
Estou tendo muita cadeira, agora, teórico-pedagógica, que é o que faltou no bacharelado, mas teve algumas cadeiras no bacharelado que os professores foram muito bons ali em mostrar uma parte de pedagogia ali, mas é deficiente. (Professor A, Bacharelado).

Essa situação já vinha sendo denunciada por autores que discutem a fragmentação da formação a partir do conhecimento, como Taffarel (2012, p. 6), que nos diz que "[...] as lacunas na formação dizem respeito à negação do conhecimento", desqualificando o professor em sua formação acadêmica, rebaixando a formação omnilateral e privilegiando a divisão social do trabalho na formação inicial.

Os relatos dos professores demonstram que a formação inicial está atrelada às necessidades de determinada parte da sociedade, em especial às ambições do sistema CREF/ CONFEF. A divisão da EF restringe o campo de atuação, mantém os professores reféns de competências aplicadas ao mercado de trabalho e promove a realização do registro no conselho da categoria. A formação fragmentada priva os trabalhadores de pensar as necessidades da sociedade de forma ampliada em favor do trabalhador, que reproduz o estabelecido na sociedade atual.

Na perspectiva de uma crítica à formação voltada aos nichos de mercado, uma expressão contundente apresentada pelos estudantes foi a necessidade de vincular a formação inicial às necessidades do mundo do trabalho. Observamos que alguns egressos têm a percepção da formação fragmentada, do trabalho independente e desarticulada entre as disciplinas, como também do distanciamento dos dois Cursos de EF da realidade concreta.

Eu acredito que a formação inicial necessita articular mais as disciplinas, muitas vezes, temos dificuldades de articular esses conhecimentos para 0 desenvolvimento das aulas. A gente sente dificuldade de fazer essa articulação de teoria e prática. Muito fragmentado [...], pouca articulação entre os professores, né? [...] É necessário discutir e debater sobre a formação inicial e a reestruturação curricular do Curso de Educação Física na instituição, objetivar uma formação omnilateral. (Professor E, Licenciatura).

Em nossa análise, esse distanciamento se estabelece, no caso do Curso de Bacharelado, pela falta de disciplinas que abordem a questão pedagógica do trato com a cultura corporal, além da falta de algumas disciplinas, como musculação, por exemplo, que, segundo alguns entrevistados, faz muita falta na atuação profissional. Outro aspecto relevante é o grande leque de possibilidades de atuação na área fitness e, nesta, as constantes mudanças de estilos e dos hits do momento (Zumba, Power mix etc.), o que exige uma constante atualização.

No caso da Licenciatura, os entrevistados evidenciaram a desarticulação entre metodologias de ensino e esportes e a carência de conhecimentos acerca do ser humano naquilo que compete à EF, contemplando o biológico, o psicológico e o social. Sentem necessidade de uma maior articulação entre os saberes conceituais da área para atuar e intervir com segurança nas suas práticas pedagógicas.

Eu fiz esse reingresso porque eu sentia necessidade de trabalhar na escola e ver a realidade da criança, como é isso no dia a dia, porque aqui dentro, no bacharelado, eu trabalhei com idosos, nos grupos de hipertensão, nos grupos de cardíacos, trabalhei com treinamento e aí lido com pessoas adultas. Meu estágio foi na ASH, na liga Nacional de Handebol, então eu trabalhei com adultos, mas eu não tive essa experiência de escola que eu tô tendo agora no Estágio I, aliás, são dois estágios, um do PIBID. (Professor A, Bacharelado). 
Sobre esse aspecto, Taffarel, Lacks e Santos Júnior (2006, p. 93) fazem uma reflexão, questionando "[...] em que bases deve-se formar professores para uma realidade complexa e contraditória que exige a formação humana na perspectiva da omnilateralidade, da emancipação humana e da transformação social".

Quando apresentamos os objetivos do desenvolvimento dessa pesquisa, observamos que a tese defendida para a divisão entre Licenciatura e Bacharelado é desenvolver as competências para que o profissional se sinta seguro para atuar no mercado de trabalho. Nesse sentido, é necessário observar, na análise, que as exigências do mercado de trabalho impõem esse contexto de retorno, levando o egresso a buscar mais qualificação e preparação para a atuação profissional. A relação se torna contraditória, as necessidades do mercado de trabalho, que são o pilar da divisão, acabam pressionando o egresso ao retorno da formação inicial em EF.

Embora um dos professores expresse que a formação inicial tenha proporcionado alcançar os objetivos pretendidos - "Eu me senti preparada, mas foi por buscar os projetos de extensão que a Universidade proporciona e na participação de grupos de estudo" (Professor F, Bacharelado) -, a questão legal, relacionada à Resolução que institui as Diretrizes Curriculares Nacionais para os Cursos de Graduação em EF, impede-os de atuar.

[...] aí eu voltei e fiz o reingresso, mas por causa de motivo, digamos assim, uma estabilidade financeira, porque o bacharel são poucos os concursos públicos que tem, né, pra bacharel. E pra licenciatura tem mais. E se eu um dia quiser voltar para a minha cidade, provavelmente seria como professora de escola, pra atuar na área, senão seria trabalhando em outro campo. (Professor D, Bacharelado).

[...]Pra complementar a graduação, né, porque não pode atuar, por exemplo, em academia e centros de treinamentos sem ter o bacharelado e eu sempre fui pra esse lado então tem que complementar pra poder atuar legalmente. (Professor I, Licenciatura).

Nesse sentido, Souza, Fuchs e Ramos (2014, p. 20) afirmam que, quando a área da EF se apropriou da legislação para elaborar suas diretrizes curriculares, prevaleceram concepções de Conhecimento e de Mundo/Mercado do trabalho, aderindo, desse modo, "[...] a uma determinada visão de conhecimento e de perfil profissional". Para os autores, a lei não limita o licenciado a atuar somente no âmbito escolar, porém "[...] o entendimento equivocado desta questão acarretou em uma lógica formativa, nesses últimos dez anos de fragmentação do conhecimento" (SOUZA; FUCHS; RAMOS, 2014p. 21).

Algumas respostas dadas pelos entrevistados nos remetem às falas de autores como Both (2011) e Nozaki (2004), que nos dizem que as atuais mudanças no mundo do trabalho vêm ampliando o desemprego e a precarização do trabalho, no que diz respeito aos salários, condições de trabalho e terceirização dos serviços. Nesse sentido, os profissionais da área de Educação Física estão sendo desvalorizados, tendo de trabalhar em mais de um local para garantir o seu sustento ou ampliar o tempo de permanência no local de trabalho para garantir o emprego.

Me formei em bacharel, fiquei dois anos contratada em uma academia aqui em Santa Maria, carteira assinada. Pedi demissão ano passado, final do ano passado. Foi mais por desgaste, muitas horas, era tipo faz-tudo. Eu fazia 10 horas, às vezes até 12 horas. Porque tipo, pra ti ganhar um salário bom... Com bastante trabalho, 0 que eu ganhava era em cima daquela parte do responsável técnico, sabe? Daí não 
era de acordo com o piso, era de acordo com o responsável. [...] Fixo na carteira era 8 horas, daí às vezes eu fazia 10, 12 horas por dia. Daí, comecei a cansar... (Professor B, Bacharelado).

Nesse contexto de perda da centralidade da EF como componente curricular da escola, a disciplina vem estendendo cada vez mais a sua atuação em um espaço não escolar. Por esse motivo, os cursos de formação vêm passando por um processo de reestruturação curricular, em que se tem como desfecho a formação de profissionais que atuarão nessa esfera. Esse processo se constitui numa importante mediação entre a EF e as novas necessidades do mundo do trabalho.

Em relação ao retorno ao Curso, percebemos um sentimento de descontentamento da maioria dos egressos, pois estes retornaram para complementar sua formação inicial e obter a certificação para atuar no mercado de trabalho, porém, quando recomeçam as atividades acadêmicas, estas, na maioria das vezes, não correspondem às suas expectativas. A ampliação do tempo de permanência no Curso parece não ser bem aproveitada devido ao fato de alguns conteúdos não serem aprofundados e estarem desassociados da realidade.

Eu acho que, por mais que tu tenhas conteúdos, é importante os professores, sei lá, avançarem nisso, sabe? Não ficarem só no debate e exposição em aula. Acho que essa parte de inserção na sociedade e no mundo, acho que na licenciatura se tem bem mais a partir dos estágios e, sei lá, acho que é apresentado mais com clareza isso para os acadêmicos. (Professor F, Bacharelado).

Os egressos, que na sua maioria já tiveram uma experiência profissional ou já atuaram como estagiários, expressam que, em algumas disciplinas, esperavam maior aprofundamento e criticidade. Também é relatado o distanciamento dos conteúdos da realidade prática, da sua inserção como futuro profissional na sociedade.

Em relação a cursar os dois cursos [...] Eu queria dizer que é perda de tempo, sabe? É, eu acho que tipo, quando é tudo novidade, o professor vai colocando e tu diz amém, só que a partir de um certo ponto tu começa a ser mais crítico e tu vê que está bem precário, eu acho que as pessoas tinham que ter mais noção que eles estão formando futuros profissionais. (Professor F, Bacharelado).

Percebemos que a ampliação no tempo de permanência vem gerando desgaste desnecessário e um dispêndio de tempo não produtivo. A falta de discussão do currículo em âmbito acadêmico provoca "mal-estar" e "incômodo" nos egressos, os quais apontam para a necessidade de reestruturação curricular, traçando um novo perfil de professor de $\mathrm{EF}$, rumo a uma formação unificada.

$\mathrm{Na}$ formação de um professor de Educação Física [...] eu acho que tem que abranger no momento inicial. Depois você tem que ver o que realmente tem afinidade e aí afunilar mais pra frente [...] eu acho que tem que fazer um currículo pra cinco anos, aproveitar mais os horários aqui dentro, dá pra fazer uma formação bem feita em cinco anos. (Professor A, Bacharelado).

Essa relação se estabelece por a formação inicial em EF estar organizada pela teoria das competências, que busca apresentar para o graduando conhecimentos baseados no progresso da técnica. Essa formação está relacionada às novas exigências do chamado "mundo globalizado", que canaliza um novo discurso para a Educação, tendo esta o papel, fundamentalmente, de se adaptar às mudanças no sistema produtivo. 
Desse modo, os conhecimentos orientadores da formação são de razão meramente instrumental. Toda essa relação acaba gerando para 0 trabalhador uma constante adaptabilidade nas suas competências, para manter-se na empregabilidade nos campos de trabalho. Isso significa que, periodicamente, o trabalhador despende tempo para se atualizar às novas necessidades geradas pelo mercado.

\section{CONSIDERAÇÕES FINAIS}

As constatações expressadas demonstram que a divisão do Curso em Licenciatura e Bacharelado desqualificou a formação do profissional, pela visão fragmentada do campo de conhecimento apresentada nos respectivos Cursos. Além disso, indiretamente, vem atendendo às demandas da regulamentação e gerência de uma pequena parcela da sociedade, o conselho da categoria (CREF/CONFEF).

Podemos perceber que o motivo do retorno dos egressos é determinado, fundamentalmente, pelo mercado de trabalho, para ampliar o seu campo de atuação. Para os entrevistados que realizaram sua primeira formação inicial no Bacharelado em Educação Física, retornar ao Curso se faz necessário para ter maiores oportunidades de realizar um concurso público, contribuindo, assim, para uma maior estabilidade financeira. No caso da Licenciatura, 0 objetivo se deve à necessidade de poder atuar no mercado liberal, complementando o seu rendimento financeiro.

De acordo com as entrevistas, é muito restrito o espaço para a discussão do currículo, no momento em que se constituíram as novas Diretrizes para a Formação dos Cursos de Licenciatura. Nesse sentido, será fundamental o diálogo em âmbito acadêmico para refletir sobre qual o perfil e identidade de professor de EF que o Curso quer formar.

A maioria dos acadêmicos entrevistados é favorável a uma formação unificada, mais abrangente, pois percebe que a sua segunda formação na graduação, apesar de estabelecer uma ampliação no ganho de conhecimento, poderia ser trabalhada em um curso único, uma vez que o objeto de estudo é o mesmo. Nesse sentido, os acadêmicos compartilham a opinião de que deveria haver uma rediscussão do currículo e do perfil de profissional a ser formado. Almejam a formação que lhes dê a possibilidade de atuação legal nos espaços escolares e informais.

\section{REFERÊNCIAS}

ANTUNES, Ricardo Luís Coltro. Adeus ao trabalho? Ensaio sobre as metamorfoses e a centralidade do mundo do trabalho. 8. ed. Campinas : Editora da UNICAMP, 2002.

ANTUNES, Ricardo Luís Coltro. 0 caracol e sua concha: ensaios sobre a Nova Morfologia do Trabalho. São Paulo: Boitempo, 2005.

BOTH, Vilmar José. Crise estrutural do capital, mudanças no mundo do trabalho e suas mediações na Educação Física. Motrivivência, v.23, n. 36, p. 45-62, jun. 2011. 
BRASIL. Conselho Nacional de Educação. Câmara de Educação Superior. Parecer CNE/CES 058/2004, de 18 de fevereiro de 2004. Institui as Diretrizes Curriculares Nacionais para os cursos de graduação em Educação Física, em nível superior de graduação plena. Brasília, 2004. Disponível em: $<$ http://portal.mec.gov.br/cne/arquivos/pdf/2007/pces058 04.pdf>. Acesso em: 30 ago. 2015.

BRASIL. Conselho Nacional de Educação. Câmara de Educação Superior. Resolução CNE/CES 07/2004, de 31 de março de 2004. Institui as Diretrizes Curriculares Nacionais para os cursos de graduação em Educação Física, em nível superior de graduação plena. Brasília, 2004. Disponível em: <http://portal.mec.gov.br/cne/arquivos/pdf/ces0704edfisica.pdf>. Acesso em: 27 ago. 2015.

BRASIL. Conselho Nacional de Educação. Câmara de Educação Superior. Resolução CNE/CES

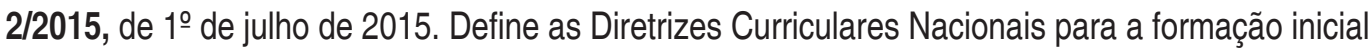
em nível superior (cursos de licenciatura, cursos de formação pedagógica para graduados e cursos de segunda licenciatura) e para a formação continuada. Brasília, 2015. Disponível em: <http://portal. mec.gov.br/index.php?option=com docman\&view=download\&alias=17625-parecer-cne-cp-2-2015aprovado-9-junho-2015\&category slug=junho-2015-pdf\&ltemid=30192>. Acesso em: 27 ago. 2015.

FARIA, José Henrique de. Economia política do poder. Curitiba: Jurará, 2004.

GENTILI, Pablo. O discurso da "qualidade" como nova retórica conservadora no campo educacional. In: GENTILI, Pablo; SILVA, Tomaz Tadeu da. (Orgs.). Neoliberalismo, qualidade total e educação: visões críticas. 2. ed. Petrópolis: Vozes, 1995. p. 111-177.

KOPNIN, Pavel Vassílyevitch. A dialética como lógica e teoria do conhecimento. Rio de Janeiro: Civilização Brasileira, 1978.

LÖWY, Michael. As aventuras de Karl Marx contra o Barão de Münchhausen: Marxismo e positivismo na sociologia do conhecimento. 8. ed. São Paulo: Cortez, 1998.

MARX, Karl. 0 capital: crítica da economia política: livro I. 28. ed. Rio de Janeiro: Civilização Brasileira, 2011.

MINAYO, Maria Cecília de Sousa. Pesquisa social: teoria, método e criatividade. 7. ed. Rio de Janeiro: Vozes,1993.

MORSCHBACHER, Marcia. Reformas curriculares e formação do (novo) trabalhador em educação física: a subsunção da formação à lógica privada/mercantil. 2012. 245 f. Dissertação (Mestrado). Pelotas: ESEF : UFPel, 2012.

NOZAKI, Hajime Takeuchi. Educação Física e reordenamento no mundo do trabalho: mediações da regulamentação da profissão. 2004.138 f. -Tese (doutorado em educação). Rio de Janeiro: UFF, 2004.

SOUZA, Maristela Silva; FUCHS, Marcius Menervini; RAMOS, Fabrício Krusche. Diretrizes Curriculares Nacionais e o Processo de Formação de Professores em Educação Física: análise a partir da legalidade, conhecimento e mundo/mercado de trabalho. Motrivivência, v. 26, n.43, p.17-29, dez. 2014.

TAFFAREL, Celi Nelza Zulke; LACKS, Solange; SANTOS JÚNIOR, Cláudio Lira. Formação de professores de Educação Física: estratégia e táticas. Motrivivência, v. 18, n.26, p.89-111, jun, 2006.

TAFFAREL, Celi Nelza Zulke; SANTOS JÚNIOR, Cláudio Lira. Formação humana e formação de professores de Educação Física: para além da falsa dicotomia licenciatura $x$ bacharelado. In: TERRA, Dinah Vasconcellos; SOUZA JÚNIOR, Marcílio (Orgs.). Formação em Educação Física \& Ciências do Esporte: políticas e cotidiano. São Paulo: Aderaldo \& Rothschild, Goiânia: CBCE, 2010. p.13-47. 
TAFFAREL, Celi Nelza Zulke. A formação de professores de Educação Física e a licenciatura ampliada. In: SEMANA DE EDUCAÇÃO FÍSICA/UFMS, 17; JORNADA DE INICIAÇÃO CIENTÍFICA DO CURSO DE EDUCAÇÃO FÍSICA/UFMS, 4. 2012. Disponível em: <http://repositorio.ufba.br/ril handle/ri/18055>. Acesso em: 7 out. 2015.

TRIVIÑOS, Augusto Nibaldo Silva. Introdução à pesquisa em Ciências Sociais: a pesquisa qualitativa em educação: o positivismo, a fenomenologia, o marxismo. São Paulo: Atlas, 1987.

UNIVERSIDADE FEDERAL DA BAHIA. FACULDADE DE EDUCAÇÃO. Fluxograma do licenciado em Educação Física. Currículo vigente a partir de 2011 do curso de Educação Física Licenciatura. Disponível em: <http://www.faced.ufba.br/sites/faced.ufba.br/files/fluxogram.pdf>. Acesso em: 29 de out. 2015. 
